\title{
Enhancing Student Success in an Introductory Chemical Engineering Course: Impact of the Cooperative Learning Strategy
}

\author{
Lueny Morell de Ramirez, Carlos Velazquez \\ University of Puerto Rico at Mayagiiez
}

\begin{abstract}
This paper describes the cooperative learning activities used y the authors in an introductory chemical engineering course, Mass and Energy Balances, at the Chemical Engineering (ChE) Department of the University of Puerto Rico at Mayagüez (UPRM). This teaching/learning strategy was part of a multi-institutional NSF-funded project that aims at increasing the graduation rate of students in science, engineering and mathematics majors on the island (the Alliance for Minority Participation Project). The in-class and out-of-class strategies utilized and their impact on student success on course outcomes are described.
\end{abstract}

\section{Brief History}

During the academic year of 1992-93, the authors participated in a pilot teaching experiment as part of a multi-institutional NSFfunded project aimed at increasing the number of minority students graduating from science, engineering and mathematics (SEM) programs. This project is entitled The Alliance for Minority Participation (AMP). One of the strategies considered to reduce the attrition rate of minority students in these programs was the identification of courses with significant student failures, so-called gatekeepers (freshman courses), and bottlenecks (upper level courses).
Then, novel teaching techniques that enhance student learning were applied to these courses. One of the techniques used was cooperative learning.

The authors tried the cooperative learning strategy in the Mass and Energy Balances course at the Chemical Engineering Department of the University of Puerto Rico at Mayagüez. As in many ChE departments, this is the first course in the program. At UPRM, engineering is a five-year program and, this course is taken by students in their fifth semester of study, parallel to differential equations and physical chemistry. The course has been known for its high attrition rate (traditionally, an average of $50-60 \%$ of students either withdraw or fail the course). Therefore, the course is considered a bottleneck course. On the average, three sections of the course are offered each semester (about 30 students per section), with each section taught by a different professor. Coordination of the course [e.g., course materials, assessment tools (exams, quizzes, homework)] is carried out by the team of faculty members teaching the course. That is, the course is considered "departmental" meaning that all faculty members teaching it must follow agreements (same test, same hour). To ensure fairness in grading the tests, problems in each test are graded by the faculty member who wrote the problem. 
The goals of using this teaching/learning strategy are to enhance student learning, reduce the attrition rate and promote student interaction in the learning process. Although Prof. Morell had been using the technique for a number of years, this was Prof. Velázquez first experience in this kind of endeavor.

\section{Theory: Learning Styles and Cooperative Learning}

According to Charles Claxton and Patricia Murrell (1987), studies of learning styles have concentrated on four areas, defined in terms of students' preferences or orientations, namely: personality, information processing, social interaction and instructional methods. Learning is affected by all these so-called "levels" of the basic characteristics of personality. These distinct research areas of learning have generated theories and models of learning. Richard Felder and Linda Silverman (1988) believe that learning takes place through a combination of these characteristics. A learning style, classifies the learner in accordance to their preferred manner of learning. It is also known that teachers tend to teach according to their preferred learning style. If there are mismatches in preferred learning styles between the learner and the teacher, poor student performance, high attrition rates and faculty frustration result (Felder, 1988).

How can faculty make the teaching/learning experience more effective and efficient? For one, by being aware of the learning styles theory. Improvement can also be achieved by using teaching strategies that affect most - if not all - the learning styles and preferences that may occur in a given classroom. What a professor teaches in the classroom has a definite impact on the student success.

There are many teaching strategies focused on specific learning styles which are recommended in the literature. A successful broad approach is cooperative learning. Felder (1991) defines cooperative learning as "the activity wherein students work in fixed groups on structured learning tasks". Effective cooperative learning must have, among other things, two aspects: positive interdependence (students work towards a common goal, and rely on one another to accomplish it), and individual accountability (each student is responsible for specific tasks).

\section{Cooperative Learning Activities and Experiences}

The authors decided to limit the use of cooperative learning strategies to only a few, in order to better assess their impact. There were in-class as well as out-of-classroom activities, and student mentor/tutors were used as resources. Basically, the following methodology was used.

The project and its expected goals were thoroughly explained to participating students at the beginning of the semester. Participation was voluntary (all students in sections 1 and 2 agreed to participate). The class was divided into groups of two (2) students, who were instructed to be seated next to each other all semester. Groups of four to five (4-5) students were also formed for out-of-class activities (meeting twice a week, for at least 2 hours). Each group of 4-5 had a tutor (in our case, a former course student who had obtained an A or B average, and preferably, who had had experience with cooperative learning). These tutors or mentors received a one-day training workshop on cooperative learning.

In-class and out-of-class activities described as follows:

Think tanks/in-class problem-solving: while lecturing, the professor would ask a question regarding a given concept and wait 1-2 minutes for a group answer. 
This strategy was used also while the professor was solving a problem in class. In the middle of the solution scheme (which was not neatly outlined previously and was worked on the blackboard with the class), he/she would stop and ask students for the next step or answer. The professor could also ask "What if I had given this piece of information instead of this one? How would this affect the solution?" Depending upon complexity, bonus points would be offered as incentives. This occurred once or twice in a 1.5 hour class session.

Quizzes: once a week a 20-minute quiz was offered to be solved in pairs in the classroom. After completing the problem, each pair would produce one solution. The quizzes would be exchanged between groups, the solution worked out by the whole class, and the quiz graded by peers.

One-minute papers: one or two minutes before the end of the class period, the professor would ask the students to write on a piece of paper what they learned in class that day. This activity was held once or twice during the semester, usually after important concepts were discussed (e.g., the energy balance). These one minute papers were not used for grading, but as a measure of the effectiveness of the student learning critical concepts.

Study groups: each group of 4-5 students met with their tutor/mentor at least once a week for two hours to solve homework problems and work through old tests.

Organization and coordination of the course proceeded as in previous semesters, as did student performance testing and grading (including final grades), This meant that the faculty team in charge decided upon material to be covered, prepared and offered on tests simultaneously. Further, the faculty team graded tests and rated student performance (this was performed rather objectively, since professor 1 grades problem 1 for all students, professor 2 grades problem 2 for all the students, and so forth). Thus, results of student performance were objective and no course section was submitted to any special "treatment" other than the cooperative learning activities.

\section{Results}

Sixty-two (62) students registered in the Mass and Energy Balances course in two sections participated in the experimental pilot cooperative learning experience (identified as sections 1 and 2). Twenty-eight (28) students did not participate (identified as section 3, or the control section). Project-wide (AMP project), a total of 777 students from various SEM disciplines and universities participated.

Outcomes of this experience proved to be extraordinary. Final grades for the Mass and Energy course's three sections in the pilot experiment (I semester 92-93) are shown in Figure 1. Overall, $77.4^{\circ} \mathrm{A}$ of the students participating in the project passed the course with a $\mathrm{C}$ or better average, compared to $28.6 \%$ in the control section. In section $1,66.7 \%$ of the students obtained $\mathrm{C}$ or better, $16.7^{\circ} / 0$ with an $\mathrm{A}$ average. In section $2,87.5^{\circ} \%$ of the students passed the course with $\mathrm{C}$ or better, $65.6 \%$ with A. While $17.9 \%$ of the students in section 3 withdrew from the course, only $3.3 \% \mathrm{did}$ so in section 1 and no students withdrew from section 2.

Project-wide (island-wide), the success was measured in terms of the percent of students performing above average compared to the previous semester (or year, in the case of 
courses offered once a year). Figure 2 shows the results for the 777 students participating that semester. Even though there was an increase of $1.3 \%$ in withdrawals from courses, there was an $8.2 \%$ increase in A's and B's, and a $9.5 \%$ reduction in C's, D's and F's.

\section{Student Experiences}

The response of the students to the pilot experiment were overall good, despite the fact that this was the first structured effort engaged using this teaching methodology. Student responses to a survey at the conclusion of the semester included remarks like:

“... (this method) forces one to be up-todate in the class and always know if you understand the material... I could discuss my doubts right there in the classroom. “

“... the student is given more confidence and liberty in the classroom... "

"I like the idea of solving the quizzes in pairs because it removed my stress."

"Having a tutor to discuss my doubts, solve problems and specially old exams, and sharing his/her experiences in the course was very good. "

\section{Other Experiences}

The outcomes of this teaching experiment seem to support one of the author's (Morell) experiences in modifying teaching methods (e.g., using cooperative learning) and the effect this produces in student learning. Figure 3 shows the author's student grades over a period of 8 semesters, showing the impact of the teaching technique. During the Summer of ' 88 , she began to use the technique in a somewhat simpler way: only in class activities mentioned in this paper, but with no mentors, or student performance assessment,

\section{Conclusions}

What happened after this semester? Prof. Morell has continued using the learning/teaching strategy with variations, with similar results. Prof. Velazquez's experience with the course was so rewarding that it helped him make an important career decision: he decided to earn a Ph.D. in Chemical Engineering to become a full time professor. He is now completing his graduate thesis at the University of Connecticut.

The AMP project group expanded the experience to other SEM faculty. Since 1992, workshops on cooperative learning have been offered at participating institutions, and many faculty members are using this teaching methodology in their classrooms. Professor Morell and other colleagues are now serving as workshop facilitators for SEM faculties islandwide. As a result, the new UPR-AMP project submitted in the Fall of ' 95 has committed to expanding/enhancing faculty training efforts of this learning strategy at participating institutions on the Island. The UPRM has begun a systemic program to train 50 faculty members from its four faculties to become trainers in teaching effectiveness strategies.

Finally, why does cooperative learning work? Why does it enhance student learning? We are not experts in this area and we do not pressure to reach unsupported conclusions, but we offer W. McKeachie's statement (which Rich Felder often refers to):

The best answer to the question, "What is the most effective method of teaching?" is that it depends on the goal, the student, the content, and the 
teacher. But the next best answer is

'<Students teaching other students. "

\section{References}

Claxton, Charles R., Murrel, Patricia H., Learning Styles: Implications for Improving

Education Practices, ASHE-ERIC Higher Education Report No. 4, Washington, DC, Association for the Study of Higher Education, 1987.

Felder, Richard M., Silverman, Linda K., Learning and Teaching Styles, Engineering Education, 78(7), April, 1988.

Felder, Richard M., Effective Teaching: A Workshop, Department of Chemical Engineering, North Carolina State University, Raleigh, NC 27695, 1991.

\section{Biographical Information}

\section{Lueny Morell de Ramirez}

Graduated from the University of Puerto Rico at Mayaguez (UPRM) in 1974, with a BS in Chemical Engineering. She completed an MS in ChE from Stanford University in 1977. Since 1978 she has been a faculty member of the ChE Department of UPRM, where she has hold several academic and administrative positions. Lueny is currently Assistant to the Chancellor for Academic Affairs and curriculum task leader at UPRM for the Manufacturing Engineering Education Partnership, a TRP project. Her R\&D interests are waste management, curriculum development and teaching/learning strategies. Lueny was recently nominated for the Chemical Manufacturers Association Teaching Excellence Award.

\section{Carlos Velazquez}

Received BS and MS degrees in Chemical Engineering from the University of Puerto Rico at Mayaguez. Currently a $\mathrm{PhD}$ candidate at the University of Connecticut. His area of research is dynamic modelling and automated controller design. Prior to pursuing graduate studies in mainland, Carlos was an instructor at the Chemical Engineering Department of the University of Puerto Rico at Mayaguez. 
Figure 1: Mass and Energy Balances

Final Grades, I semester 92-93
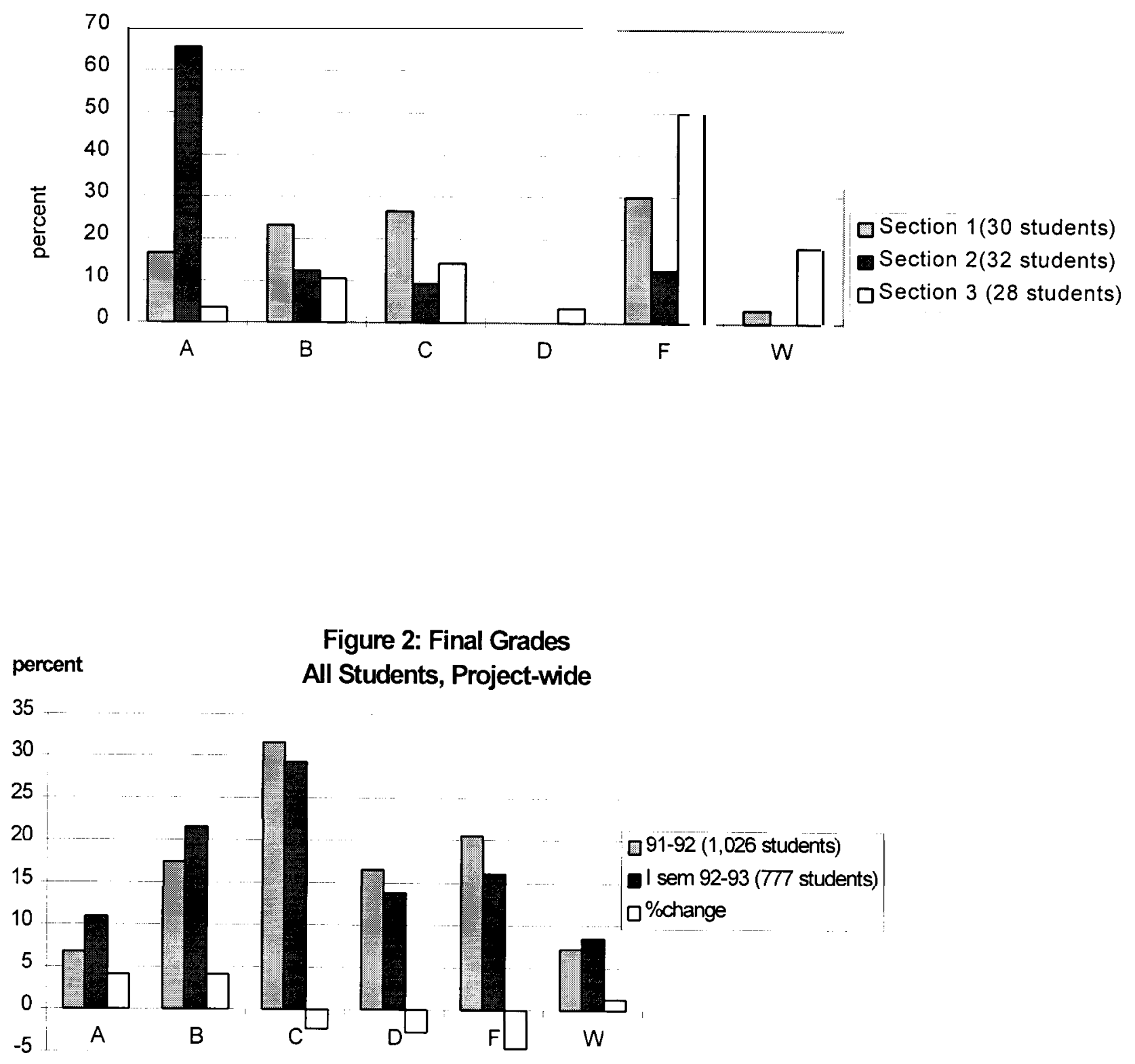
Figure 3: Mass and Energy Balances Course History,
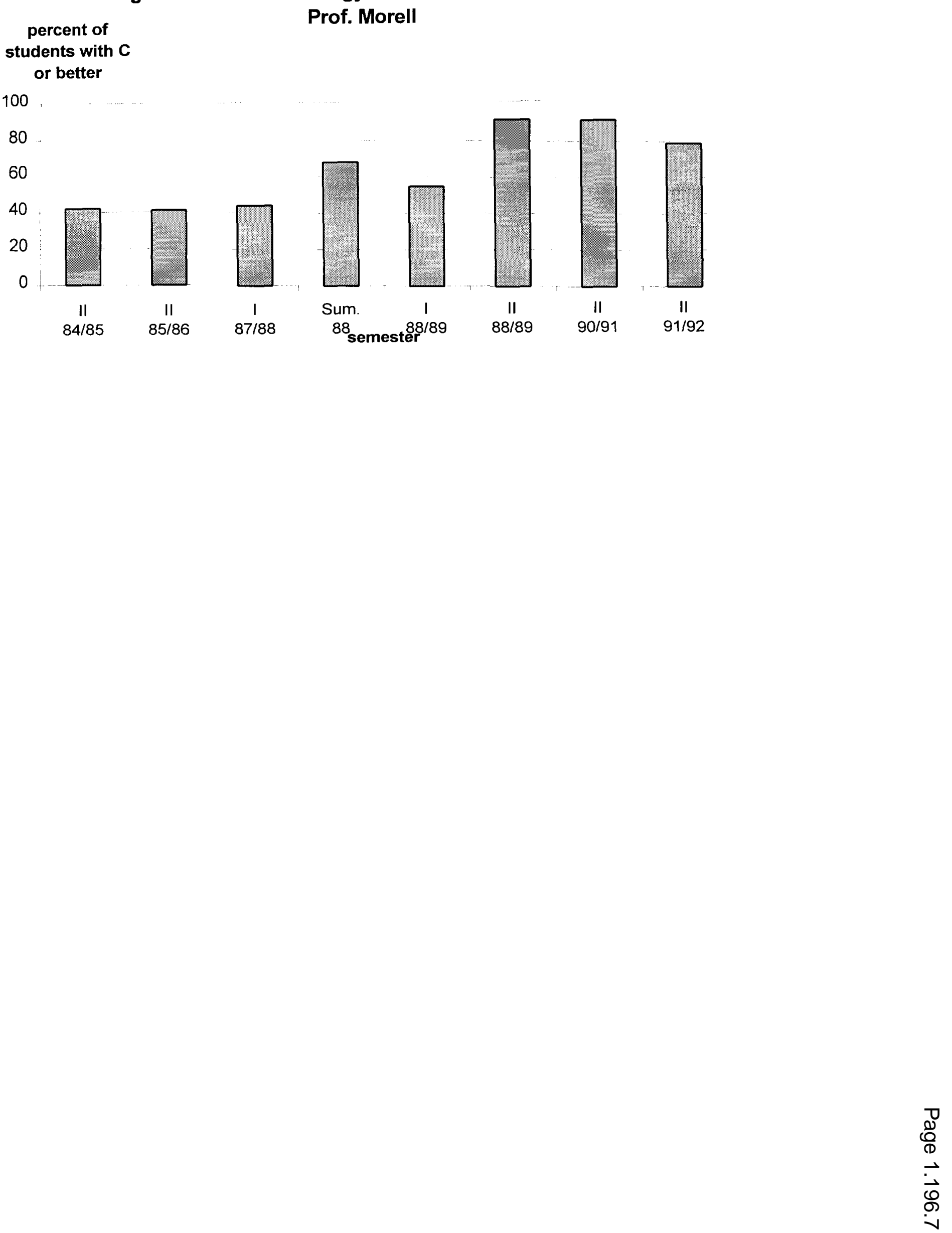